\title{
A rare presentation of esophageal actinomycosis in an immunocompetent patient
}
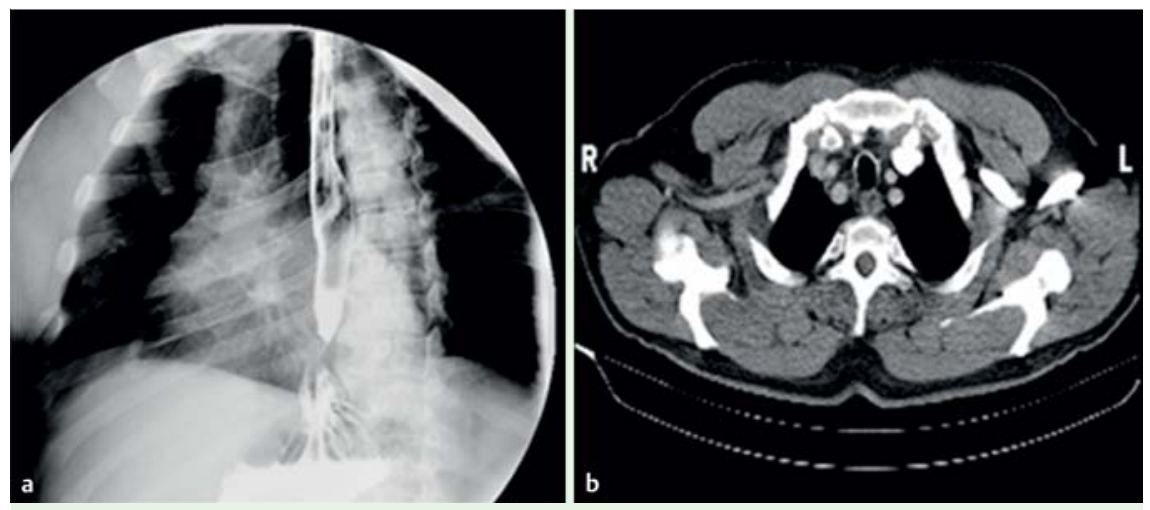

Fig. 1 Investigations in a 56-year-old man with a 2-month history of odynophagia, heartburn, and dysphagia. a Barium esophagogram showing a hiatal hernia, filling defects, and an area of irregularity in the mucosa of the mid-distal esophagus. b Computed tomography (CT) scan showing a hiatal hernia, irregularity and thickening of the esophagus, but no evidence of any fistula (image from the mediastinal window).
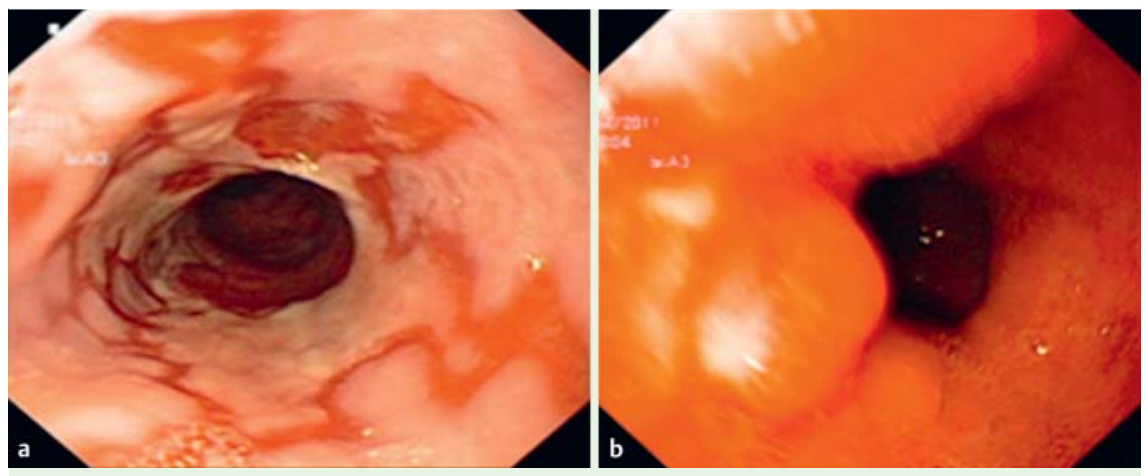

Fig. 2 Upper gastrointestinal endoscopy images showing: a white plaques in the mid-esophagus; b multiple 1-2-cm shallow ulcers and a $3 \times 2-\mathrm{cm}$, irregular, malignant-appearing ulcer in the distal esophagus, and a hiatal hernia.

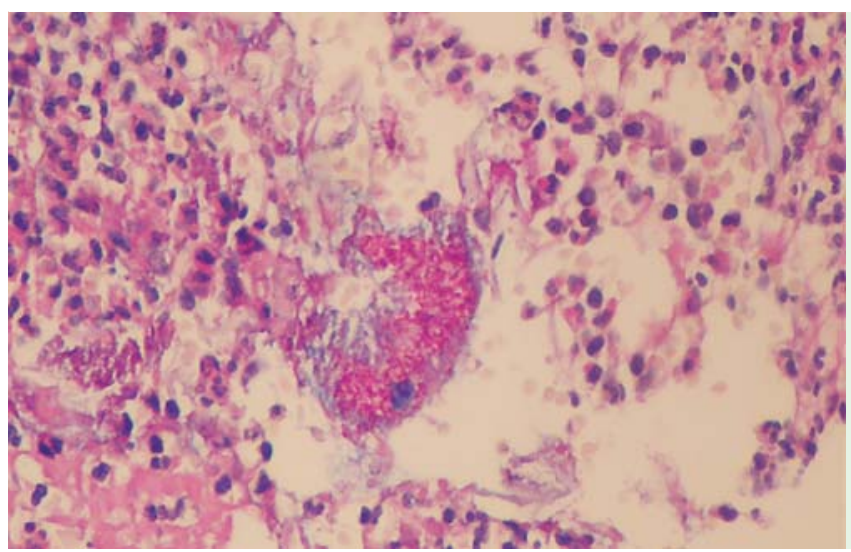

Fig. 3 Histologic examination of a hematoxylin and eosin (H\&E)stained biopsy specimen showing discrete sulfur granules in the ulcerated tissue consistent with infection by Actinomyces species (magnification $\times 400$ ).
A 56-year-old man was referred to our hospital with a 2-month history of odynophagia, heartburn, and dysphagia. His physical examination was normal. Laboratory investigations showed a normal complete blood count, normal biochemistry panel, and negative serology for human immunodeficiency virus (HIV). A barium esophagogram revealed a hiatal hernia with a filling defect and irregular mucosal areas in the mid-distal esophagus ( Fig. 1a). A computed tomography (CT) scan confirmed the hiatal hernia, mucosal irregularity, and thickening of the esophagus ( $\bullet$ Fig. 1 b).

An upper gastrointestinal endoscopy showed white plaques predominantly in the mid esophagus, multiple 1 -2-cm shallow ulcers and a $3 \times 2-\mathrm{cm}$, irregular, malignant-appearing ulcer in the distal esophagus, and the hiatal hernia ( $\bullet$ Fig. 2 ).

Histological examination of biopsies taken from the esophagus revealed discrete sulfur granules consistent with infection by Actinomyces species. No dysplasia, malignancy, fungi, or viral inclusions were present ( Fig.3).

Intravenous penicillin G (24000U per 24 hours) was administered for 2 weeks. Following this, amoxicillin clavulanate was administered twice daily for 6 weeks. The patient improved clinically following medical treatment. At 10 weeks, a repeat upper gastrointestinal endoscopy showed marked healing of the shallow ulcers, reduced size of the malignant-appearing ulcer, and improvement in the surrounding inflammation.

Actinomycosis is a rare, chronic, suppurative disease caused by Actinomyces spp. that are present in the normal flora of the oral cavity and gastrointestinal tract. It is characterized by the formation of sulfur granules. Esophageal involvement is an extremely rare presentation of Actinomyces spp. particularly in immunocompetent subjects [1,2].

Currently, the exact mechanism of esophageal actinomycosis is not known. We suggest that the dysmotility of the esophagus in patients with hiatal hernia may be a possible mechanism for co-occurrence of actinomycosis.

Long-term, high-dose antibiotic therapy is required for a successful outcome. Penicillin is the drug of choice. Ampicillin, amoxicillin, tetracycline, macrolides, clindamycin, chloramphenicol, and cephalosporins have also been reported to be effective [ 3 , 4]. 
Endoscopy_UCTN_Code_CCL_1AB_2AC_3AZ

\section{Competing interests: None}

\section{H. Korkmaz ${ }^{1}$, U. Kutluana², M. S. Bugdaci ${ }^{2}$, I. Kucukosmanoglu ${ }^{3}$}

${ }^{1}$ Division of Gastroenterology, Selcuk University, Selcuklu, Konya, Turkey

2 Department of Gastroenterology, Konya Education and Research Hospital, Meram, Konya, Turkey

${ }^{3}$ Department of Clinical Pathology, Konya Education and Research Hospital, Meram, Konya, Turkey

\section{References}

1 Vinson PP, Sutherland CG. Esophagobronchial fistula resulting from actinomycosis: report of a case. Radiology 1926; 6: 63-64

2 Poles MA, McMeeking AA, Scholes JV et al. Actinomyces infection of a cytomegalovirus esophageal ulcer in two patients with acquired immunodeficiency syndrome. Am J Gastroenterol 1994; 89: 1569-1572

3 Lee SH, Kim HJ, Kim HJ et al. Primary gastric actinomycosis diagnosed by endoscopic biopsy: case report. Gastrointest Endosc 2004; 59: 586-589

4 Russo TA. Agents of actinomycosis. In: Mandell GL, Bennett JE, Dolin R, eds. Mandell, Douglas and Bennett's Principles and Practice of Infectious Diseases. 5th edn. Philadelphia: Churchill Livingstone; 2000: 2645-2654

\section{Bibliography}

DoI http://dx.doi.org/

10.1055/s-0033-1344067

Endoscopy 2013; 45: E181-E182

(c) Georg Thieme Verlag KG

Stuttgart · New York

ISSN 0013-726X

\section{Corresponding author}

\section{H. Korkmaz, MD}

Selcuk Üniversitesi

Selçuklu Tıp Fak. Alaeddin Keykubad Kampusü 42075 Selçuklu

Konya

Turkey

Fax: +90-332-2416065

husein68@hotmail.com 